\title{
Saltational evolution of the heterotrimeric G protein signaling mechanisms in the plant kingdom
}

\author{
Daisuke Urano, ${ }^{1,2 \star}$ Natsumi Maruta, ${ }^{3}$ Yuri Trusov, ${ }^{3}$ Richard Stoian, ${ }^{1}$ Qingyu Wu, ${ }^{4}$ \\ Ying Liang, ${ }^{1}$ Dinesh Kumar Jaiswal, ${ }^{1}$ Leena Thung, ${ }^{2}$ David Jackson, ${ }^{4}$ \\ José Ramón Botella, ${ }^{3}$ Alan M. Jones ${ }^{1,5 *}$
}

\begin{abstract}
Signaling proteins evolved diverse interactions to provide specificity for distinct stimuli. Signaling complexity in the G protein (heterotrimeric guanosine triphosphate-binding protein) network was achieved in animals through subunit duplication and incremental evolution. By combining comprehensive and quantitative phenotypic profiles of Arabidopsis thaliana with protein evolution informatics, we found that plant heterotrimeric G protein machinery evolved by a saltational (jumping) process. Sequence similarity scores mapped onto tertiary structures, and biochemical validation showed that the extra-large Ga (XLG) subunit evolved extensively in the charophycean algae (an aquatic green plant) by gene duplication and gene fusion. In terrestrial plants, further evolution uncoupled XLG from its negative regulator, regulator of $G$ protein signaling, but preserved an $\alpha$-helix region that enables interaction with its partner $G \beta \gamma$. The ancestral gene evolved slowly due to the molecular constraints imposed by the need for the protein to maintain interactions with various partners, whereas the genes encoding XLG proteins evolved rapidly to produce three highly divergent members. Analysis of $A$. thaliana mutants indicated that these $G \alpha$ and XLG proteins all function with $G \beta \gamma$ and evolved to operate both independently and cooperatively. The XLG-G $\beta \gamma$ machinery specialized in environmental stress responses, whereas the canonical $G \alpha-G \beta \gamma$ retained developmental roles. Some developmental processes, such as shoot development, involve both $G \alpha$ and XLG acting cooperatively or antagonistically. These extensive and rapid evolutionary changes in XLG structure compared to those of the canonical $\mathrm{G} \alpha$ subunit contrast with the accepted notion of how pathway diversification occurs through gene duplication with subsequent incremental coevolution of residues among interacting proteins.
\end{abstract}

\section{INTRODUCTION}

Heterotrimeric guanosine triphosphate (GTP)-binding proteins ( $\mathrm{G}$ proteins) are evolutionarily conserved signaling complexes that originated in eukaryotes $(1,2)$. In the inactive state, the $\mathrm{G} \alpha$ subunit of this complex is bound by guanosine diphosphate (GDP) and forms a heterotrimer with the G $\beta \gamma$ dimer. Activation of the associated receptor by ligand binding induces the exchange of GDP for GTP in Go, changing its conformation and causing it to dissociate from the $\mathrm{G} \beta \gamma$ dimer and enabling both $\mathrm{G} \alpha$ and $\mathrm{G} \beta \gamma$ to separately bind to target proteins (3). The regulator of $\mathrm{G}$ protein signaling (RGS) protein catalytically promotes GTP hydrolysis by Go, thus restoring formation of the inactive heterotrimer. The G $\alpha-G \beta \gamma$ and $\mathrm{G} \alpha$-RGS interactions are ancestral and were inherited by most eukaryotes under multiple strong selective pressures that included nucleotide binding, catalytic rate optimization, maintenance of several protein-protein interaction (PPI) surfaces, protein folding and stability, and subcellular localization (4). G $\alpha$ genes multiplied, incrementally evolved their residues within the defined constraints, and created subtype-specific cellular responses in the animal clade. However, it remains unknown how the $\mathrm{G}$ protein network acquired signaling

\footnotetext{
1Department of Biology, University of North Carolina, Chapel Hill, NC 27599, USA. ${ }^{2}$ Temasek Life Sciences Laboratory, 1 Research Link, National University of Singapore, Singapore 117604, Singapore. ${ }^{3}$ Plant Genetic Engineering Laboratory, School of Agriculture and Food Sciences, University of Queensland, Brisbane, Queensland 4072, Australia. ${ }^{4}$ Cold Spring Harbor Laboratory, Cold Spring Harbor, NY 11724, USA. ${ }^{5}$ Department of Pharmacology, University of North Carolina, Chapel Hill, NC 27599, USA.

${ }^{*}$ Corresponding author. Email: daisuke@tll.org.sg (D.U.); alan_jones@unc. edu (A.M.J.)
}

complexity outside the metazoans, because this radiation of $\mathrm{G}$ protein complexes began in the metazoans, and the G protein complex evolved little outside the metazoans. For example, in plants, there is a single class of canonical $\mathrm{G} \alpha$ subunit (2) that has a three-dimensional (3D) structure nearly identical to that of human $\mathrm{G} \alpha$ (5). A. thaliana $\mathrm{G}$ protein $\alpha$ subunit 1 (GPA1) is the prototype of the plant canonical $\mathrm{G} \alpha$. We propose that $\mathrm{G}$ protein signaling in divergent organisms, such as plants, evolved quite differently than that in animals.

The plant $\mathrm{G}$ protein pathway diverged through gene duplication, gene fusion, and extensive steric alterations, resulting in the emergence of a $\mathrm{G} \alpha$ subunit profoundly different from canonical $\mathrm{G} \alpha$, named extra-large $\mathrm{G} \alpha$ (XLG). The Arabidopsis genome encodes one canonical Go (AtGPA1), three atypical XLGs (AtXLG1, AtXLG2, and AtXLG3), one G $\beta$ (AGB1), three $\mathrm{G} \gamma$ subunits (AGG1, AGG2, and AGG3), and one RGS protein (AtRGS1) (2). The C-terminal half of XLG proteins shares homology with the canonical $\mathrm{G} \alpha$ subunits but poor conservation of residues (28 to $32 \%$ identity to canonical Go in Arabidopsis). The N-terminal half lacks homology to any characterized domain but contains a putative nuclear localization signal and a cysteine-rich region (6). In Arabidopsis, XLG signaling controls root morphology and stress responses (7-11), whereas the canonical $\mathrm{G} \alpha$ retains a wide range of developmental roles (12-14) and functions in light sensing (15) and the abscisic acid response (16).

We showed in this study that the $\mathrm{G}$ protein pathway diverged through gene duplication and extensive steric changes near the base of the Streptophyta, a lineage including charophycean algae and terrestrial plants, evolving a profoundly different XLG-like subunit. Informatics analyses of protein evolution, combined with biochemical validation, revealed that 
XLGs preserve their interaction with their binding partner G $\beta \gamma$ but barely hydrolyze GTP and do not interact with RGS. These observations suggest that XLGs have lost nucleotide dependency of conformation or depend on a mechanism of nucleotide cycling distinct from that of other eukaryotic $\mathrm{Go}$ proteins. An Arabidopsis phenome of 30 quantitated traits revealed four G protein signaling pathways controlled dominantly, cooperatively, or antag-

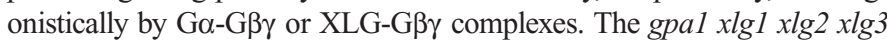
quadruple mutant we describe fully phenocopied the G $\beta$-null mutant agb1, thus explaining why the loss of the $\mathrm{G} \alpha$ subunit alone does not phenocopy the G $\beta$-null mutant $(8,13,14)$. The lack of a mutant combining the null alleles of these four subunits made previous conclusions on redundancy equivocal $(7,8)$. The XLG protein emerged in charophycean algae, a group of freshwater plants closely related to land plants. As the last common ancestors of charophycean algae and green plants invaded land (17), they underwent extensive physiological, morphological, and architectural alterations (17-19). Adaptation to land likely involved large genetic changes and repurposing of existing components in the signaling networks. The ancestral algal XLGs therefore likely contributed to the adaptation to this new environment.

Evolution of XLG proteins contrasts starkly with the evolution of the animal and fungal heterotrimeric $\mathrm{G}$ protein pathways, which occurred by small changes of coevolving residues on effectors and receptors to form new signaling functions. This is the predominant interpretation for most signaling network evolution. We show how both incremental and saltational evolution of the $\mathrm{G}$ protein pathway occurred in plants.

\section{RESULTS}

\section{Saltational evolution of plant XLG}

Informatics analyses revealed massive evolution of XLGs. Over evolutionary time, the canonical Arabidopsis Ga strictly conserved its 3D structure (5) and residues that mediate the interaction with guanine nucleotides, the G $\beta \gamma$ dimer, and its cognate RGS protein (20). In contrast, XLGs lost several residues essential for nucleotide binding and GTP hydrolysis $(7,10)$, yet XLGs have some detectable GTP hydrolysis activity in vitro (21). The XLG proteins did not experience the same evolutionary constraints as did animal and plant canonical $\mathrm{G} \alpha$ subunits. The C-terminal half of plant XLGs is homologous to AtGPA1 (fig. S1A), and the N-terminal half is homologous to an uncharacterized protein family (fig. S1, B and C). The XLGs originated within Streptophyta (land plants and their ancestral green algal group) by gene fusion. XLG proteins underwent substitutions in the $\mathrm{G} \alpha$ domain more than five times faster than did canonical $\mathrm{G} \alpha$ subunits near the base of the land plant phylogenetic tree and further became separated into two distinct groups in angiosperms (fig. S1).
According to the theory of protein evolution (22), functionally indispensable sites, in this case the catalytic core residues, are subjected to an enormous selective pressure against mutations, resulting in invariant residues in multiple sequence alignments (MSAs). Using high-quality MSAs, we analyzed Jensen-Shannon divergence (JSD) scores (23) of animal and plant $\mathrm{G} \alpha$ proteins to quantify selective pressure at individual residues in the Go domains and then to infer PPI specificities. JSD scores represent similarity in a range from 0 to 1 , where the greatest value corresponds to the highest similarity at each position along the MSA. Both animal and plant G $\alpha$ proteins exhibited a highly conserved surface area, as illustrated by the high JSD scores of these residues, including the G $\beta \gamma$-binding interface (Fig. 1, A and B) $(1,24)$, indicating a comparable evolution of canonical plant and animal $\mathrm{G} \alpha$ subunits for increasing network diversity while preserving a heterotrimeric complex. The JSD scores of homologs of AtGPA1 and AtXLG3 within the angiosperms revealed poorly constrained XLG positions on the three switch regions (filled colored circles, Fig. 1C and fig. S2). The switch regions undergo a conformational change upon activation, predicting that XLGs do not bind to nucleotides or do not do so in the same manner as do canonical Go subunits.

G $\alpha$ subunits interact with RGS proteins and G $\beta \gamma$ dimers primarily at the switch I and the switch II regions (3). A conserved lysine on switch

\section{a}

A
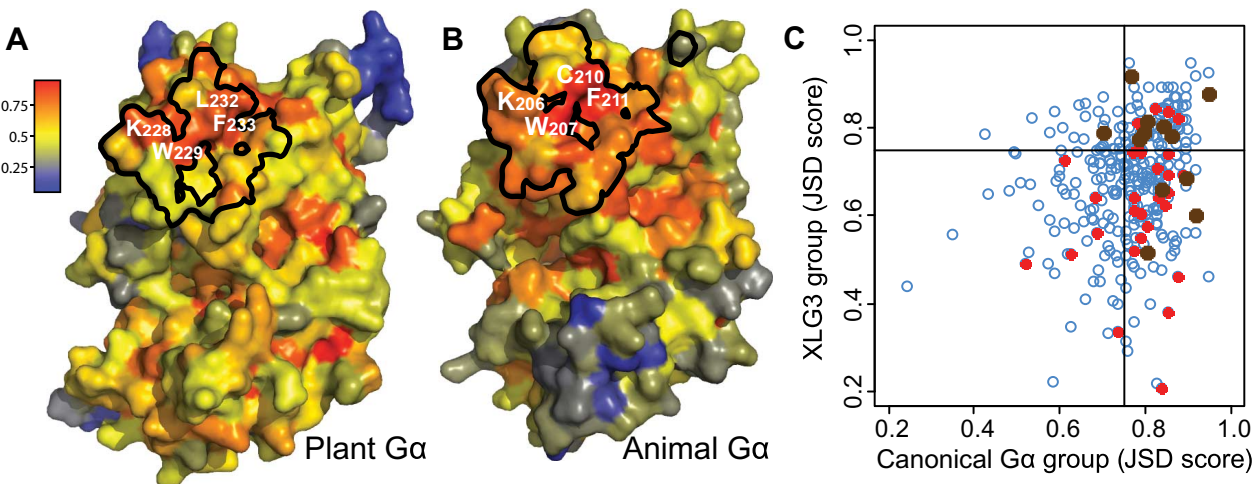

D
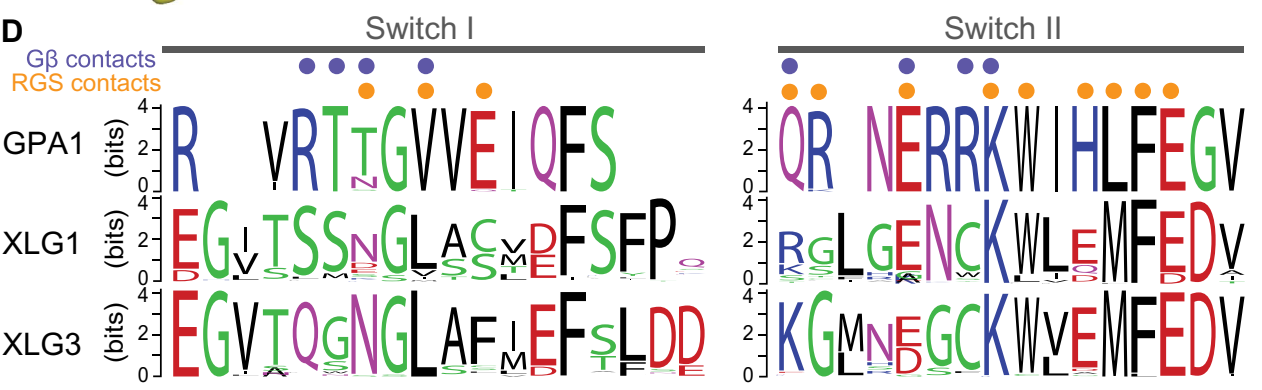

Fig. 1. Divergence of animal and plant $G \boldsymbol{\alpha}$ residues. (A and B) JSD scores mapped onto tertiary structures of plant and animal $\mathrm{G} \alpha$ proteins. The scores were calculated from 664 animal $\mathrm{G} \alpha$ sequences and 274 plant $\mathrm{G} \alpha$ and XLG sequences. Greater values (red) indicate higher similarity and therefore more evolutionary constraint at a particular position, and smaller values (blue) indicate lower similarity. Black lines delineate atoms within $4.5 \AA$ from $G \beta \gamma$. White text indicates residues in the switch II region of Arabidopsis AtGPA1 or bovine Gat1. (C) JSD scores calculated with canonical plant $\mathrm{G} \alpha$ sequences against XLG3 sequences in angiosperms. Each dot or circle represents a JSD score at one position in the MSAs of the Ga domains. Brown dots indicate the G $\beta \gamma$ contact sites on three switch regions. Red dots show other switch region residues. All other positions are indicated by blue circles. Reference lines indicate 0.75 . Note that several switch region residues in XLG3 sequences are strictly conserved, including G $\beta$-binding sites on switch II. (D) Switch I and switch II regions of angiosperm canonical G $\alpha$ (GPA1), XLG1, and XLG3 sequences. Conservation, based on the Shannon entropy, was estimated by the WebLogo program (41) and shown with bit scores on the $y$ axis. Blue and orange dots represent AtRGS1 or G $\beta$ contact residues inferred from mammalian structures (24). 
II-equivalent to AtGPA1-Lys ${ }^{228}$, AtXLG3-Lys ${ }^{667}$, and bovine Gat1Lys $^{206}$ - docks into a negatively charged pocket formed by two aspartic acids in G $\beta$ (24), whereas another conserved hydrophobic residue equivalent to AtGPA1-Leu ${ }^{232}$, AtXLG3-Met ${ }^{671}$, and bovine Got1-Cys ${ }^{210}$ forms a hydrophobic core with adjacent hydrophobic residues in $\mathrm{G} \beta$ (24). Two conserved hydrophobic residues, equivalent to AtGPA1-Trp ${ }^{229}$ and AtGPA1-Phe ${ }^{233}$, also contribute to the hydrophobic interaction between the $\mathrm{G} \alpha$ subunit and the G $\beta \gamma$ dimer (fig. S3). XLGs, despite rapid evolution from the ancestor, conserved the central residues for making contact with G $\beta$ (Fig. 1D and fig. S2, D and E) but underwent mutation of most residues in the switch I region. The amino acid changes in XLGs include an evolutionarily conserved threonine that is indispensable for the Go-RGS interaction in animals and plants (Fig. 1D and fig. S4) $(20,25,26)$. The conservation scores also indicated that residues required for nucleotide hydrolysis were mutated in XLGs. AtXLG1 and AtXLG3 displayed weak but detectable GTP hydrolysis in vitro (fig. S5B), suggesting the requirement for a guanosine triphosphatase-activating protein to support nucleotide cycling in vivo. It was reported that calcium increases the GTP hydrolysis rate of AtXLG2 (21), but evidence here indicates that this is not likely to be true for AtXLG1 or AtXLG3 (fig. S5B). In summary, the evolutionary analyses predict that XLG proteins bind to the G $\beta \gamma$ dimer but not to RGS proteins.

We validated the evolutionary inference of the protein couplings with in vitro biochemistry, using glutathione $S$-transferase (GST)-tagged G $\alpha$ and AtXLGs and His-tagged AtRGS1 proteins expressed in Escherichia coli and a G $\beta \gamma$ (AGB1-AGG1) dimer produced in Sf9 insect cells (Fig. 2 and fig. S5) (27). AtGPA1 and AtXLG3 bound G $\beta \gamma$ in the presence of GDP (Fig. 2, A and B), suggesting that AtXLG3 constrained and used the con-

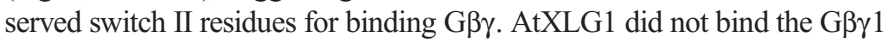
complex, possibly because its preferred binding partner is G $\beta \gamma 2$, as observed in yeast cells (8). The presence of aluminum fluoride, a stabilizer of the G $\alpha$ catalytic transition state, abolished the AtGPA1-G $\beta \gamma$ interaction but not the AtXLG3-G $\beta \gamma$ interaction, suggesting that this interaction is independent of a conformational change of AtXLG3 and that AtXLG3 has lost its nucleotide dependency. The plant $G$ protein complex may have an uncharacterized binding interface between $\mathrm{G} \alpha$ and $\mathrm{G} \gamma$ conferring the subtype-dependent couplings between AtXLGs and AGB1-AGG dimers, because a previous experiment showed that AGB1 was not needed for AtXLGs to interact with $\mathrm{G} \gamma$ in yeast two-hybrid assays (8). We detected an interaction between AtGPA1 and AtRGS1 only in the presence of aluminum fluoride (Fig. 2B) but no interaction between AtXLG1 or AtXLG3 and AtRGS1, supporting our prediction that XLGs rapidly evolved near the base of the land plant phylogenetic tree and lost RGS-mediated negative regulation.

\section{Biological traits attributed to $\mathrm{G} \alpha-\mathrm{G} \beta \gamma$ and XLG-GB $\gamma$ complexes}

AtGPA1 and AtXLGs have multiple physiological roles in planta. Null mutations in Arabidopsis G $\beta$ (agbl) influence more than 20 measurable traits ranging from morphology to environmental responses (2), whereas null alleles of the canonical G $\alpha$ (gpal) or the XLGs $(x \lg 1, x \lg 2$, and $x \lg 3)$ only partially recapitulated the $a g b 1$ phenotypes $(2,7,8,12,13,28)$. However, it is possible that the predominant phenotypes of agbl may arise from a heterotrimer-independent role of G $\beta \gamma$. Previous studies $(7-10)$ examined $x \lg$ mutant phenotypes but did not include a gpal $x \lg 1 x \lg 2 x \lg 3$ quadruple mutant and therefore were not complete genetic epistasis analyses. To determine the functional relationship between the GPA1-G $\beta \gamma$ and XLG-G $\beta \gamma$ pathways, we combined null alleles of the genes encoding $\mathrm{G} \alpha$ and all three XLGs and analyzed the phenotypic profile of this quadruple mutant (gpal xlg123) compared to other single and compound $\mathrm{G}$ protein null mutants
(Fig. 3, figs. S6 to S11, and Table 1). Some of the 30 phenotypes we quantified had not previously been examined in G protein mutants.

The gpal $x \lg 123$ quadruple mutant fully phenocopied the archetypal agbl leaf shape (Fig. 3, A and B), an agbl trait apparently different from the gpal or $x \lg 123$ mutant phenotypes $(12,29)$. Longitudinal leaf growth decreased partially in the gpal and the $x \lg 123$ null mutants and more severely in the gpal $x \lg 123$ quadruple, agb1 single, and agg1 agg2 agg3 triple (agg123) mutants. Leaf width, on the other hand, was increased in the gpal mutants and reduced in the $x \lg 123$ mutants (Fig. 3A). The gpal $x \lg 123$ quadruple, agb1 single, and the agg123 triple mutants displayed wild-type leaf width, an additive effect of the gpal and $x \lg 123$ mutations. The same genetic relationship was observed for seed and silique morphology (fig. S6), suggesting the additive or antagonistic effect of $G$ protein pathways in shoot development.

The agbl mutation confers a larger root mass due to a longer primary root and increased number of lateral roots (13), but this is not the case for the gpal single or $x \lg 123$ triple null mutants $(9,10,13)$. The gpal and $x \lg 123$ mutants displayed a marginal increase in primary root length and the number of lateral roots, whereas the gpal $x \lg 123$ quadruple mutant recapitulated the larger $a g b 1$ root mass phenotype (Fig. 3C and fig. S7). Similarly, mutations in gpal and $x \lg 123$ additively suppressed the abscisic acid response in seed germination (fig. S7C), increased the sensitivity to high glucose (fig. S7D), and increased both the length and width of the SAM (fig. S8). In contrast to the enlarged SAM, the gpal and agbl mutants had a reduced number of epidermal cells in the hypocotyl, an in vivo indicator of reduced cell proliferation in the shoot $(13,14)$. We imaged hypocotyls of the mutants at high
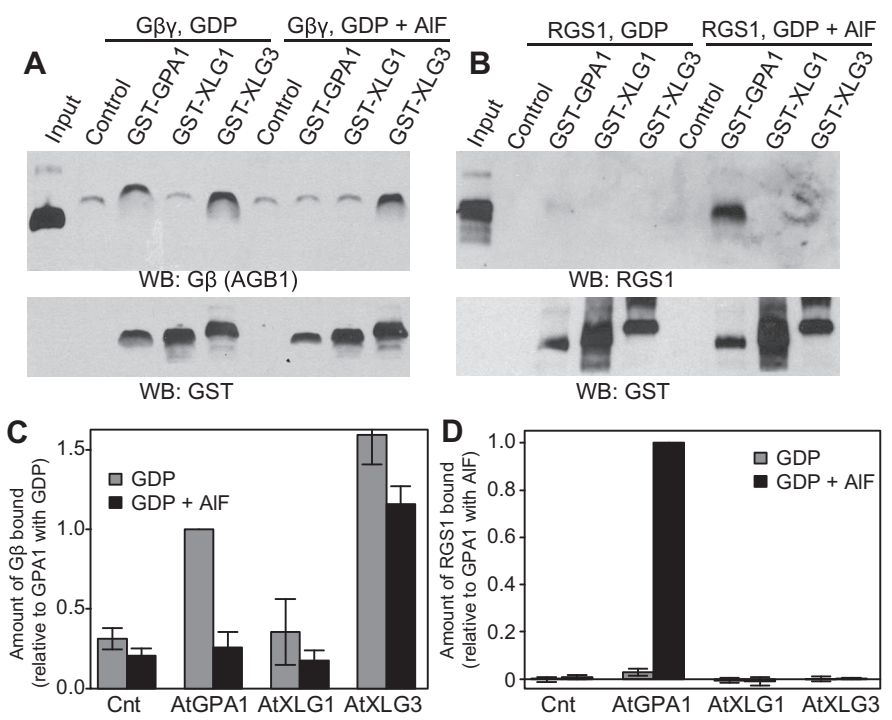

Fig. 2. Arabidopsis XLG physically couples with G及 $\gamma$ but not with RGS. In vitro interaction between GST-tagged AtGPA1, AtXLG1, or AtXLG3 and His-tagged $G \beta \gamma 1$ or AtRGS1. (A and B) G $\beta \gamma 1$ (AGB1-AGG1) protein or the cytoplasmic domain of RGS1 was pulled down by GDP-bound $G \alpha$ proteins (full-length AtGPA1 or Go domain of AtXLG1 or AtXLG3) with or without aluminum fluoride (AIF) using glutathione-Sepharose. AGB1-AGG1, RGS1, and GST-G $\alpha$-XLG proteins were separated on a polyacrylamide gel and detected with antibodies that recognize AGB1, AtRGS1, or GST. The control lanes show binding of G $\beta \gamma$ or RGS1 to glutathione-Sepharose alone. WB, Western blot. ( $C$ and $D$ ) The abundance of AGB1 or AtRGS1 was quantified with ImageJ and shown as relative values of interaction with AtGPA1. Error bars show SDs of two independent assays. 
magnification using scanning electron microscopy (Fig. 3D and fig. S9). The number of epidermal cells decreased slightly in the $x \lg 123$ mutant $(11 \%)$, whereas in the gpal, agbl, agg123, and gpal xlg123 mutants, the decrease was substantial (30 to 49\%) (Fig. 3D), indicating that cell proliferation is primarily controlled by AtGPA1 rather than the XLGs.

We next examined biotic and abiotic stress responses of $\mathrm{G}$ protein mutants (Fig. 3E and figs. S10 and S11). The agbl single, $x \lg 123$ triple, and the agg123 triple null mutants displayed hypersensitivity to multiple stresses $(2,28,30,31)$, whereas the gpal mutant had wild-type stress responses. Sodium chloride treatment severely arrested leaf growth in the $x \lg 123$ triple, gpal $x \lg 123$ quadruple, agb1 single, and agg123 triple mutants but not in the gpal mutant or Col-0 control (Fig. 3E). The same set of G protein mutant alleles (xlg123, gpal xlg123, agb1, and agg123) displayed a similar pattern of responses to fungal and bacterial infections - the bacterial peptide flg22 (an activator of the pathogen-associated molecular pattern defense response), AtPEP1 (a peptide activator of the danger-associated molecular pattern response), and the nucleoside antibiotic tunicamycin (an activator of the unfolded protein response) (figs. S10 and S11) - indicating

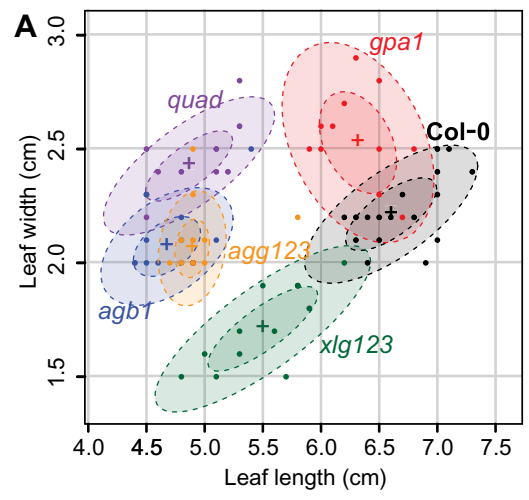

C

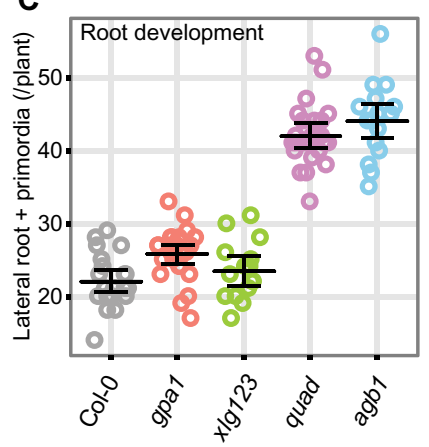

D

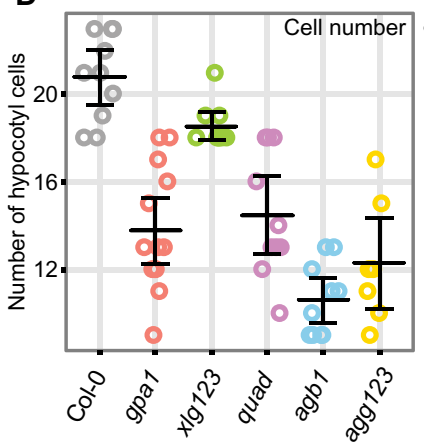

E

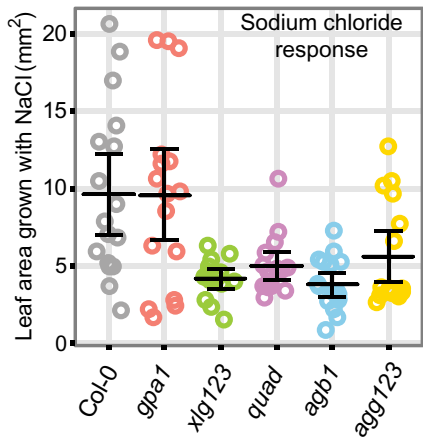

Fig. 3. Plant $G \boldsymbol{\alpha}$ and XLG cooperate in regulation of $G \boldsymbol{\beta} \gamma$ traits. (A) Leaf length and width of wild-type (Col-0 ecotype) and $G$ protein mutants grown for 5 weeks under short-day conditions. Each dot represents length and width of a single leaf from different plants. Plus signs (+) denote centroids for each genotype. Inner and outer ellipses include 50 and $90 \%$ of the data, respectively. (B) Representative rosettes grown for 30 days. (C) Number of lateral roots plus lateral root primordia at day 16. The indicated genotypes were grown on the $1 / 2$ Murashige \& Skoog (MS) medium under short days. (D) Number of cells along the longitudinal axis of etiolated hypocotyls. Hypocotyls were grown for 2 days under darkness. (E) Leaf area of Arabidopsis plants treated with sodium chloride. Genotypes indicated are as follows: Col-0, Columbia-0; gpa1, gpa1-3; xlg123, xlg1-1 xlg2-1 xlg3-1 triple mutant; quad, gpa1-3 xlg1-1 xlg2-1 xlg3-1 quadruple mutant; agb1, agb1-2; and agg123, agg 1-1c agg2-1 agg3-3triple mutant. (C to E) Raw values of the measurement (colored circles), the means (horizontal black lines), and the error bars representing 95\% confidence intervals. Additional physiological traits are quantitated in figs. S6 to S11. Mean values with SEs, sample sizes ( $n)$, and statistical analyses are summarized in Table 1. that pathways involved in multiple stress responses are biased toward XLGs rather than canonical Go. The three isoforms of XLGs enable further signaling complexities in Arabidopsis, because the three isoforms redunregulate sodium chloride and tunicamycin resistance (8), whereas onEediates cellular responses to pathogens and flg22 peptide (7) Environmental conditions on the land fluctuate more rapidly than aquatic environmental conditions. Streptophyte terrestrialization would have rethe adaptation to different pathogens and new environmental conditions that the preterrestrialized algal ancestors to land plants would not have experienced. existing patterns of plant $\mathrm{G}$ protein pathways observed in Arabidopsis mutants. A hierarchical clustering of the phenotypic profile classified the requireint for $\mathrm{G}$ protein pathways into four categories: (i) additive bi-parallel, ment); (ii) antagonizing, in which AtGPA1 and XLG signaling antagonize one another (leaf width); (iii) AtGPA1-biased (number of hypocotyl epidermal cells); and (iv) XLG-biased (shoot length and stress responses) (Fig. 4D). Principal components analysis of the first two components, which jointly account for $89 \%$ of the overall variance in the phenome data (Fig. 4B), showed an apparent cluster composed of the agbl, agg123, and gpal xlg123 mutants.

\section{DISCUSSION}

The divergence of the ancestral Ga into $\mathrm{G} \alpha$ plus three XLGs redistributed the functionality of the single ancestral $G$ protein unit into two parallel pathways. A charophycean alga invaded land from fresh water $\sim 500$ million years ago and adapted to diverse environments (17). This drastic change in environments presumably drove a rapid and massive evolution of plant signaling networks. Gene duplication of G $\alpha$ occurred early in the ancestor of land plants and resulted in the appearance the XLG-G $\beta \gamma$ complex, but it is unclear from gene sequences if XLG evolution was under selective pressure or whether this highly divergent $\mathrm{Go}$. homolog had an important function at all. Many XLG functions documented in our Arabidopsis phenome, such as stress responses, contributed to the success of plant terrestrialization, whereas only a few functions of the canonical $\mathrm{G} \alpha$ seem to be relevant in this respect. Thus, the XLG-G $\beta \gamma$ complex was likely essential for plants to adapt to the marked changes and instability of the newly colonized environment.

Our phenotypic profiling also suggests that AtGPA1 and the XLGs, along with three AGGs, account for all the $G$ protein signaling complexity in Arabidopsis; however, it is still unclear how AtGPA1, XLGs, and G $\beta \gamma$ transmit signals from upstream regulators to 
Table 1. Summary of physiological data. Shown are means \pm SEs of the means, with sample numbers in parentheses and statistical significance symbols determined by either parametric or nonparametric oneway analysis of variance (ANOVA). * or ** indicates significant difference from the Col- 0 value, with the $P$ value less than 0.05 or 0.01 , respectively, using the parametric test. $\dagger$ or $\dagger \dagger$ indicates significant difference at the $P$ value less than 0.05 or 0.01 , respectively, using the nonparametric test. n.s., no significant difference at the $P$ value of 0.05 . Note that seeds from Col-0 plants from both A.M.J.'s and D.J.'s laboratories were used for the measurement of shoot apical meristem (SAM) size. See fig. S8 for statistical information of SAM data. ROS, reactive oxygen species; a.u., arbitrary units; N.A., not analyzed.

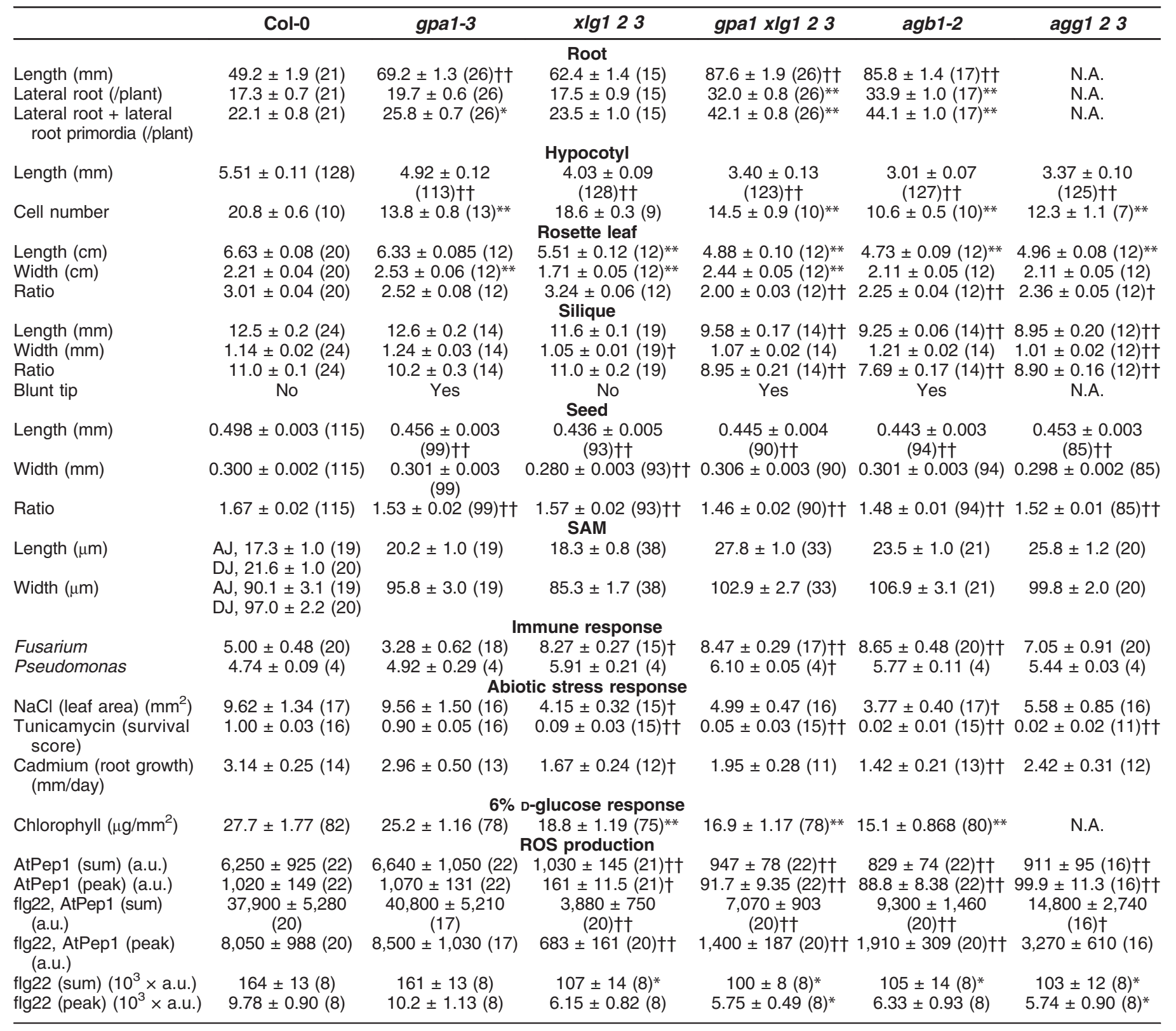

downstream effectors. Unlike the canonical mechanism of $\mathrm{G}$ protein regulation, AtXLG2 undergoes phosphorylation by the bacterial peptide flg22, presumably leading to trimer dissociation and ROS production (32). A similar phosphorylation mechanism may function in other XLG-biased pathways. Besides the divergent roles of the two G $\alpha$ subtypes, G $\beta \gamma$ dimers potentially transmit signals to other effectors in addition to inhibiting nucleotide exchange on GPA1 and XLGs, as they do in animals and yeast.
Genes encoding $\mathrm{G}$ proteins were independently lost several times during the $\sim 1$ billion years from an ancestral archaeplastidan until becoming conserved genes in a land plant ancestor, indicating a weak biological constraint

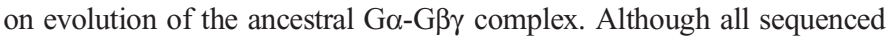
land plant genomes conserve XLG genes (33), genes comprising the canonical G $\alpha-\mathrm{G} \beta \gamma$ machinery have been less constrained in the plant kingdom. The bryophyte Physcomitrella patens, which separated from a vascular 

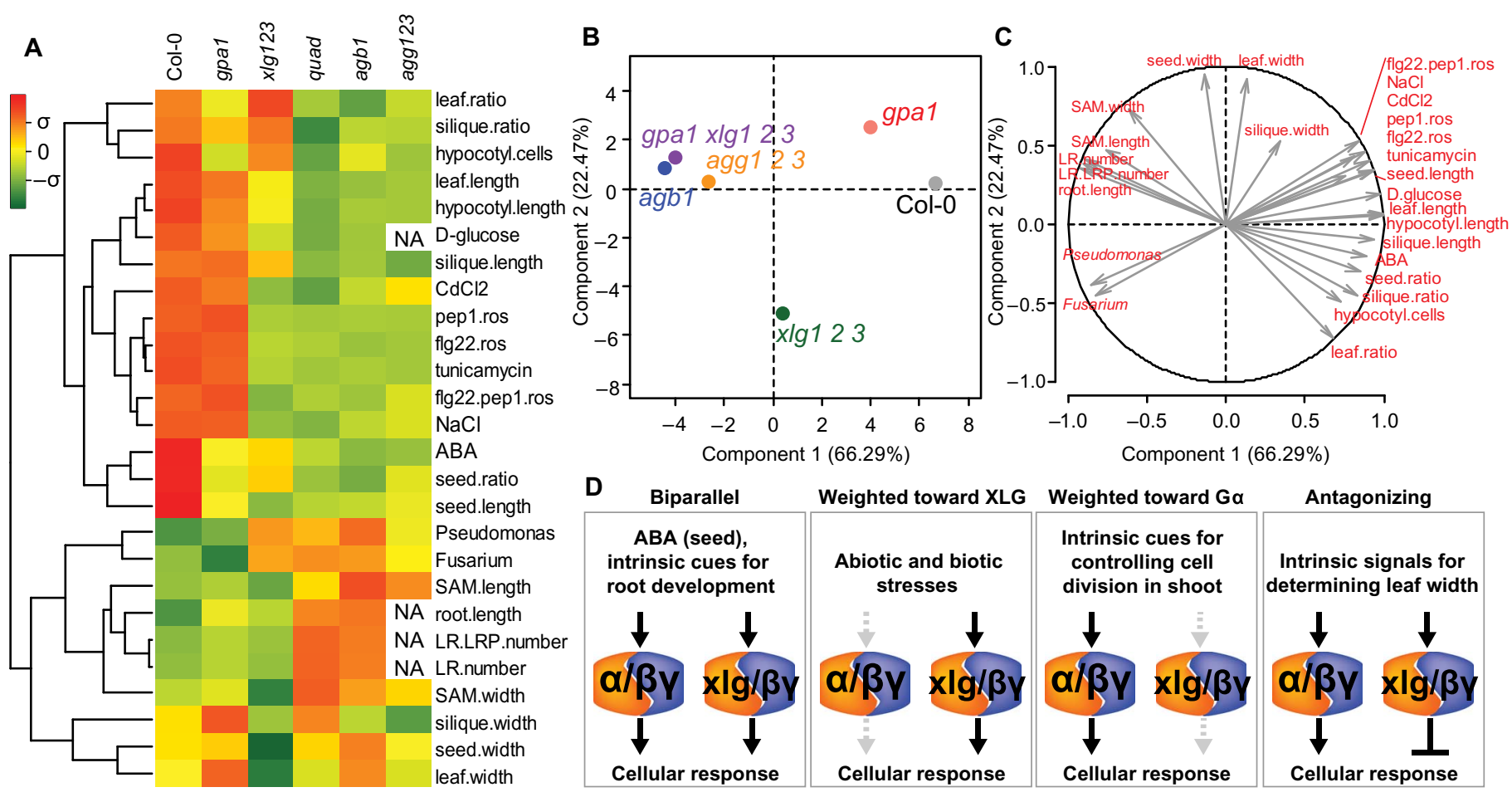

Fig. 4. G $\boldsymbol{\alpha}-\mathrm{G} \boldsymbol{\beta} \gamma$ and $X L G-G \beta \gamma$ complexes enable four biological responses in Arabidopsis. (A) Phenotypic profile of wild-type Col-0 plants and $\mathrm{G}$ protein mutants. The heat map indicates a decrease (green) or an increase (red) with respect to the mean value of six genotypes, as quantitated in Table 1. Each row represents individual physiological traits ordered by the hierarchical clustering algorithm. NA, not analyzed; LR, lateral root; LPR, lateral root + lateral root primordia; SAM, shoot apical meristem. (B and C) Principal components analysis of the phenotypic patterns for six Arabidopsis genotypes. (B) The first two components are plotted. The first component

plant lineage near the land plant base $\sim 450$ million years ago (34), has an XLG-G $\beta \gamma$ complex but lacks the canonical G $\alpha$ and RGS genes, supporting our conclusion of the loss of XLG interaction with RGS. Also, most cereals in the monocot lineage lack RGS proteins, which inhibit signaling by canonical G $\alpha$ but not signaling by XLG (Fig. 2). These gene preservation patterns, along with the narrow physiological roles (Fig. 4), suggest that the canonical Go machinery inherited a small fraction of ancestral G protein functions, specifically those involved in development.

In both plants and animals, $G$ protein networks evolved to cooperatively regulate cellular responses. Of central importance to the adaptability of these networks is the ability to form multiple combinations of trimers using different $\mathrm{G} \alpha$ and $\mathrm{G} \gamma$ proteins $(7,20,35,36)$. In plants, diversification of the $\mathrm{G}$ protein network first involved the multiplication of $\mathrm{G} \alpha$ genes in an ancestor preceding the emergence of land plants (fig. S1), creating G $\alpha$ and XLG ancestors, and $\mathrm{G} \gamma$ genes, which later evolved into three angiosperm $\mathrm{G} \gamma$ classes (36). Eukaryotic Go genes, including both animal and canonical plant $\mathrm{G} \alpha$, evolved under similar selective pressures, highly constraining the residues involved in binding $\mathrm{G} \beta$ and the residues involved in nucleotide binding and hydrolysis. Whereas canonical plant Go homologs slowly evolved and retained these typical Go properties of the prototypical plant $\mathrm{G} \alpha$ ancestor, XLG genes underwent comprehensive mutation of the residues that mediate these properties, thus conferring new properties to the signaling pathway. shows the additive effects of the gpa1 or xlg123 mutants, and the second component represents the opposite effect between the gpa1 and xlg123 mutants. (C) Factor analysis of phenotypic traits that contribute to the first two components. The first component is attributed to various phenotypic traits observed in $\mathrm{G}$ protein mutants, and the second component is mainly associated with shoot width traits. (D) Four distinctive $\mathrm{G}$ protein pathways made by canonical $\mathrm{G} \alpha-\mathrm{G} \beta \gamma$ and nonconventional $X L G-G \beta \gamma$ complexes mediate responses to different endogenous or environmental cues.

Gradual versus saltational evolution has been debated since the origin of evolutionary theory itself. As related in a series of letters between Thomas Henry Huxley and Charles Darwin (37), Darwin's credence of "natura non facit saltum" (nature does not make jumps) was cautioned wisely by Huxley. The evolution of the plant $G$ protein pathway is here suggested as a noteworthy example where both Darwin's gradual and Huxley's saltational models of evolution may have operated in parallel. The extensive evolution of XLG subunits, which was completed at least 500 million years ago when plants adapted to terrestrial environments, led to more complex signaling processes in response to extracellular cues. The emergence of XLG pathways may have empowered ancestral terrestrial plants to rapidly adapt to the harsh environmental changes at the earliest stage of plant colonization of land.

\section{MATERIALS AND METHODS}

\section{Sequence retrieval and MSA}

$\mathrm{G} \alpha$ homologous sequences were retrieved from the UniProt proteome, UniProtKB, and Phytozome 10 databases using the HMMER or BLAST programs. Picea glauca, Pinus taeda, Marchantia polymorpha, Klebsormidium flaccidum, and Homo sapiens sequences were collected from the National Center for Biotechnology Information expression sequence tag database or our previous publication (20). The retrieved sequences were aligned 
with the MAFFT software version 7 (38). Redundant sequences and positions having $90 \%$ or more gaps were removed. Sequences having 240 or more residues in the $\mathrm{G} \alpha$ domain, corresponding to residues from $\mathrm{Glu}^{35}$ to $\mathrm{Arg}^{374}$ of AtGPA1, were used for phylogenetic analysis with the R package phangorn (39). An initial phylogeny of 309 sequences was constructed by the neighbor-joining method with the Jones-Taylor-Thornton substitution model. The maximum likelihood method estimated model parameters including edge length, tree topology, $\gamma$ rate, and proportion of variable size. Two hundred bootstrap iterations were performed with maximum likelihood consideration of tree topology and edge length estimations. H. sapiens Gail and Gaq sequences were used as outgroups. A phylogenetic tree, shown in fig. S1, includes organism names and gene identifiers in the UniProt or Phytozome databases.

\section{Structure homology modeling}

AtGPA1 structure was modeled in a complex with AGB1-AGG1 or RGS1 using the Modeller software version 9.15 (40). The sequences used are AtGPA1 (residues from $\mathrm{Lys}^{36}$ to $\mathrm{Arg}^{374}$ ), AtXLG3 (residues from Lys ${ }^{428}$ to $\mathrm{Lys}^{816}$ ), AGB1 (residues from $\mathrm{His}^{10}$ to $\mathrm{Ala}^{369}$ ), AGG1 (residues from $\mathrm{Ala}^{25}$ to $\mathrm{Leu}^{58}$, and from $\mathrm{Gly}^{64}$ to Leu ${ }^{78}$ ), and AtRGS1 (residues from Lys ${ }^{298}$ to Lys ${ }^{413}$ ). Template atomic structures of animal G $\alpha \beta \gamma$ and Arabidopsis AtGPA1 were obtained from the Protein Data Bank (PDB). Their PDB identifiers are 1GP2 (GDP-bound $\mathrm{G \alpha}_{\mathrm{i} 1}$ with $\mathrm{G} \beta \gamma$ ), $1 \mathrm{GOT}$ (GDP-bound $\mathrm{G}_{\mathrm{t} / \mathrm{i}}$ chimera with $\mathrm{G} \beta \gamma$ ), 3AH8 (GDP-bound $\mathrm{G} \alpha_{\mathrm{q}}$ with $\mathrm{G} \beta \gamma$ and the inhibitor YM-254890), and 2XTZ (GTP-bound AtGPA1). The mammalian G $\alpha \beta \gamma$ structures were solved in their inactive GDP-bound form (24), and the published AtGPA1 structure was in its active GTP $\gamma$ S-bound form (5). The homology model of GPA1-G $\beta \gamma$ was constructed with GDP. The template structures were structurally aligned with each other and then aligned with an AtGPA1-G $\beta \gamma$ amino acid sequence in the Modeller program. Seven structures were modeled automatically with the default settings except that molecular dynamics refinement speed was set to "very slow." The homology models of the G $\alpha$ and RGS complex were generated with the same procedure and the template structures as described previously (25). AtXLG3-G $\beta \gamma$ structures were constructed using the GPA1-G $\beta \gamma$ structure as a template. Modeled structures were assessed by the discrete optimized protein energy (DOPE) score, and the structures that have the lowest DOPE value were used for further analyses. The PyMOL v1.7.2 program was used for identifying interface residues, coloring atoms, and making final images. Atoms within $5 \AA$ from G $\beta \gamma$ or AtRGS1 proteins were defined as interface sites.

\section{Entropy measurement at each position in the MSA}

The Shannon entropy and JSD scores estimate conservation of residues for each position in MSA. Because erroneous gaps in MSA cause underestimation of divergence scores, we removed protein sequences that have less than $95 \%$ of positions aligned with their Arabidopsis homologs AtGPA1, AtXLG1, or AtXLG3. Angiosperm G $\alpha$ and XLG proteins were retrieved as described above. The remaining sequences of 81 canonical $\mathrm{G} \alpha$, 94 XLG1 and XLG2, and 99 XLG3 homologs were processed. Shannon entropy and JSD scores were calculated with the BLOSUM62 substitution matrix for estimating substitution probabilities and the Protein Residue Conservation Prediction program for background frequency of residue variability (23). The JSD score was mapped on the G $\alpha$ structures. The Shannon entropy was calculated with Sequence Logos (41).

\section{Plasmids and proteins}

Complementary DNAs (cDNAs) for expressing A. thaliana XLG1 (residues from $\mathrm{Arg}^{481}$ to the $\mathrm{C}$ terminus) and XLG3 (residues from $\mathrm{Lys}^{428}$ to the $\mathrm{C}$ terminus) were cloned from adult leaves of Col-0 plants. The cDNAs were subsequently cloned into the E. coli vectors pDEST15 and pDEST17, which express GST or $6 \times$ histidine-tagged proteins. The expression vectors for AtGPA1 and AtRGS1 (residues from Lys ${ }^{284}$ to the C terminus) were as described (42). The expression plasmids were transformed into the ArcticExpress RP strain. The E. coli was grown in liquid LB medium in a $37^{\circ} \mathrm{C}$ shaker, moved to a $12^{\circ} \mathrm{C}$ shaker for inducing protein expression overnight with 0.3 to $0.5 \mathrm{mM}$ isopropyl $\beta$-D-1-thiogalactopyranoside, and then harvested by centrifugation. The $6 \times$ histidine-tagged proteins were purified as described (20).

\section{In vitro pull down}

About $0.5 \mu \mathrm{g}$ of Arabidopsis G $\beta_{1} \gamma_{1}$ or $1 \mu \mathrm{g}$ of His6-RGS1 (Lys ${ }^{284}$ to the C-terminus) was incubated with or without $100 \mu \mathrm{g}$ of GST-GPA1, GST-XLG1, or GST-XLG3 in $200 \mu$ of $25 \mathrm{mM}$ tris- $\mathrm{HCl}$ (pH 8.0), $50 \mathrm{mM} \mathrm{NaCl}, 1 \mathrm{mM}$ dithiothreitol, $1 \mathrm{mM}$ phenylmethylsulfonyl fluoride, $10 \mathrm{mM} \mathrm{MgCl}_{2}$, and $50 \mu \mathrm{M}$ GDP. A transition state of $\mathrm{G} \alpha$ was prepared by adding $10 \mathrm{mM} \mathrm{NaF}$ and $100 \mu \mathrm{M} \mathrm{AlCl}$. GST-tagged proteins were then precipitated with glutathione-Sepharose 4B and washed with the buffer. The precipitated proteins were separated on an SDS-polyacrylamide gel electrophoresis gel and visualized with a Western blot method using antibodies specific for G $\beta$, RGS1, and GST.

\section{Plant materials}

Arabidopsis genotypes used are the wild-type Col-0 and its transferred DNA (T-DNA) insertion lines of gpal-3 (14), xlg123 triple (xlg1-1 xlg2-1 xlg3-1) (10), agb1-2 (13), agg triple (agg1-c agg2-1 agg3-3) (36), or gpal xlg123 quadruple (gpal-3 xlg1-1 xlg2-1 xlg3-1). T-DNA insertions in GPA1 and $X L G$ genes were examined with polymerase chain reaction (fig. S12).

\section{Hypocotyl length}

Thirty-five milliliters of $1 / 2$ MS medium with $1 \%$ sucrose, $1 \%$ phytoagar, and $0.5 \%$ MES was poured into $100-\mathrm{mm}$ square plates. The $\mathrm{pH}$ of the medium was adjusted to 5.7 with potassium hydroxide. Arabidopsis seeds were sterilized with $33 \%$ bleach and $0.01 \%$ Triton X-100 for 10 min and then washed with sterilized water five times. Three rows of about 10 seeds each were sown onto the plates, with each row consisting of a particular genotype. The plates were then sealed with air-permeable tape and vernalized at $4^{\circ} \mathrm{C}$ in the dark for at least 72 hours. The plates were then placed horizontally under 200 to $230 \mu \mathrm{mol} \mathrm{s}-1 \mathrm{~m}^{-2}$ of light for 2 hours to stimulate germination of the seeds and situated vertically in darkness at $23^{\circ} \mathrm{C}$ for 48 hours. The hypocotyls were imaged at the end of the 48-hour period, and their length was measured using the ImageJ software.

\section{Leaf and silique development}

Wild-type and mutant plants were grown for 5 weeks in a short-day chamber with a 24-hour cycle of 8 hours of light at $150 \mu \mathrm{mol} \mathrm{s}^{-1} \mathrm{~m}^{-2}$ and 16 hours of darkness. Leaf length, from the petiole to the leaf tip, and width were measured on the longest leaf of each rosette. Silique phenotypes were imaged and quantitated when leaves started turning yellow.

\section{Root length and lateral root formation}

Eighty milliliters of $1 / 2$ MS medium with $1 \%$ sucrose, $1 \%$ phytoagar, and $0.5 \%$ MES was poured into $150-\mathrm{mm}$ square plates. Sterilized Arabidopsis seeds were treated with $10 \mu \mathrm{M}$ gibberellic acid (GA3) at $4^{\circ} \mathrm{C}$ in the dark for more than 3 days and then sown onto the plates in a row with eight seeds of the same genotype. The plates were sealed with air-permeable tape and placed in a short-day chamber with a cycle of 8 hours of light at 200 to $230 \mu \mathrm{mol}$ $\mathrm{s}^{-1} \mathrm{~m}^{-2}$ and 16 hours of darkness. Root images were taken at day 16 and quantified in length using ImageJ. After imaging, the roots were stained with a solution of $54.025 \%$ water, $45 \%$ acetic acid, and $0.075 \%$ carmine. Lateral roots and lateral root primordia were counted using a light microscope. 


\section{Tunicamycin resistance}

Seeds were sterilized and treated with $10 \mu \mathrm{M}$ GA3 under darkness. Forty milliliters of $1 / 2$ MS medium with $1 \%$ sucrose, $1 \%$ phytoagar, $0.05 \% \mathrm{MES}$, and tunicamycin $(75 \mathrm{ng} / \mathrm{ml})$ at $\mathrm{pH} 5.7$ (adjusted with potassium hydroxide) was poured onto $100-\mathrm{mm}$ square plates. The plates were divided into four quadrants, and nine seeds of a single genotype were sown per quadrant. After the plates were sealed with air-permeable tape, they were placed under continuous $\operatorname{dim} \operatorname{light}\left(30 \mu \mathrm{mol} \mathrm{s}{ }^{-1} \mathrm{~m}^{-2}\right)$ at $23^{\circ} \mathrm{C}$. The plates were imaged at day 14 , and the number of germinated and surviving plants was quantified.

\section{Sodium chloride resistance}

Five-day-old Arabidopsis seedlings grown on $1 / 2$ MS medium plates were transferred to $1 / 2$ MS medium plates with $1 \%$ sucrose, $1 \%$ phytoagar, $0.05 \%$ MES, and $125 \mathrm{mM}$ sodium chloride ( $\mathrm{pH}$ 5.7). The plates were placed horizontally under continuous dim light at $23^{\circ} \mathrm{C}$ for 5 days. The seedlings were imaged, and then the leaf area was quantified with the ImageJ program.

\section{Cadmium resistance}

Ten 3-day-old Arabidopsis seedlings grown on $1 / 2$ MS medium plates were transplanted to $1 / 2 \mathrm{MS}$ medium plates with or without $60 \mu \mathrm{M}$ cadmium chloride. Seedlings were oriented along a line with the roots below and hypocotyls above. Each plate contained all genotypes. Duplicate plates for each treatment were included. The positions of the root tips of the seedlings were marked immediately after transfer using a scalpel to scratch the plastic. The plates were placed vertically in a short-day chamber with a 24-hour cycle of 8 hours of light at $150 \mu \mathrm{mol} \mathrm{s}^{-1} \mathrm{~m}^{-2}$ and 16 hours of darkness. At 24-hour intervals after transplant, the positions of the root tips were marked and the distance between the marked intervals was determined using a caliper and a microscope.

\section{ROS production with flg22 and pathogen inoculation assays}

Leaf discs (6 $\mathrm{mm}$ in diameter) were excised from mature leaves of 6-weekold plants grown at $23^{\circ} \mathrm{C}$ in short-day conditions (8-hour light/16-hour dark) and placed into individual wells of a 96 -well plate. Two hundred microliters of water was added into each well, and the plate was kept at $23^{\circ} \mathrm{C}$ in the dark overnight. Water was removed, and $150 \mu \mathrm{l}$ of reaction buffer $[10 \mathrm{mM}$ tris$\mathrm{HCl}(\mathrm{pH} 8.5)]$ was added, followed by the addition of $30 \mu \mathrm{l}$ of luminol/ peroxidase solution ( $200 \mathrm{mg} \mathrm{ml}^{-1}$ each) and $20 \mu \mathrm{l}$ of $10 \mu \mathrm{M}$ flg22 $(1 \mu \mathrm{M}$ final concentration) into each well. Luminescence was measured in the GloMax 96 Microplate Luminometer (Promega). Resistance to Pseudomonas syringae pv. tomato (Pto) DC3000 and Fusarium oxysporum was evaluated as described previously $(7,43)$.

\section{ROS production with AtPep1 peptide}

Seeds of wild-type Col-0 and G protein mutants were sown on soil pots pretreated with water. The seeds were stratified by keeping the pots at $4{ }^{\circ} \mathrm{C}$ in the dark for 3 to 4 days. After seed stratification, pots were transferred to a Percival incubator (Percival Scientific) at $21^{\circ} \mathrm{C}$, relative humidity of $85 \%$, and photosynthetically active radiation of $180 \mu \mathrm{mol} \mathrm{m}^{-2} \mathrm{~s}^{-1}$ under short-day (8-hour light/16-hour dark) conditions. Seedlings, at the two-leaf stage, were transferred individually into 2.5 -inch square pots and allowed to grow for 4 to 5 weeks. A luminol-based assay was used to monitor the kinetics of ROS production in leaf disc samples from these plants. Leaf discs were prepared from 4- to 5-week-old plants. We randomly selected leaves of similar size from each plant, prepared the leaf discs, and incubated the discs in a 96-well plate in water with or without $100 \mathrm{nM}$ flg22 for 16 hours. Before measurement, the water or the flg 22 solution was removed, and $100 \mu \mathrm{l}$ of assay solution [luminol $\left(17 \mu \mathrm{g} \mathrm{ml}^{-1}\right)$, horseradish peroxidase $\left(10 \mu \mathrm{g} \mathrm{ml}^{-1}\right)$, and $100 \mathrm{nM}$ AtPep1] was added to each well. Luminescence was measured using a microplate reader (SpectraMax Plus 384, Molecular Devices) and acquired over time.

\section{SAM size}

Arabidopsis seedlings were grown under short-day conditions (8-hour light $/ 16$-hour dark at $23^{\circ} \mathrm{C}$ ) for 4 weeks and then dissected and fixed in $10 \%$ formalin, $5 \%$ acetic acid, and $45 \%$ ethanol. The fixed tissues were sequentially washed with $70,85,95$, and $100 \%$ ethanol for 30 min each wash and then immersed in an ethanol-methyl salicylate solution (1:1) for an additional $60 \mathrm{~min}$. The tissues were then cleared in 100\% methyl salicylate for 2 hours. The SAM was imaged with a Leica DMRB microscope with a Leica MicroPublisher 5.9 RTV digital camera system. The SAMs were measured by ImageJ.

\section{Data analyses and statistical tests}

All data were plotted with mean values, with error bars representing 95\% confidence intervals. One-way ANOVA and the Tukey's multiple comparison test were used to measure the statistical significance between wild-type Col-0 and mutant groups. $*$ or ** was used to signify significance of differences having $P$ values less than 0.05 or 0.01 , respectively. n.s. stands for not significant at the $P$ value of 0.05 . A nonparametric method, the Kurskal-Wallis one-way ANOVA followed by the Dunn's multiple comparison test, was applied to some physiological data, which did not meet the assumptions of parametric ANOVA. $\dagger$ or $\dagger \dagger$ indicates significant difference at the $P$ value less than 0.05 or 0.01 , using the nonparametric test. All statistical information is shown in Table 1.

\section{SUPPLEMENTARY MATERIALS}

www.sciencesignaling.org/cgi/content/full/9/446/ra93/DC1

Fig. S1. Phylogeny of plant $\mathrm{G} \alpha$ and XLG proteins.

Fig. S2. JSD in canonical $G \alpha$ and noncanonical XLG protein sequences.

Fig. S3. A modeled structure of the Arabidopsis AtGPA1-AGB1-AGG1 complex.

Fig. S4. A modeled structure of the Arabidopsis AtGPA1-AtRGS1 complex.

Fig. S5. Recombinant GST-AtGPA1, AtXLG1, and AtXLG3 proteins.

Fig. S6. Leaf, seed, and silique morphology of $G$ protein mutants.

Fig. S7. Root morphology and $A B A$ and sugar response of $G$ protein mutants.

Fig. S8. The SAM size of Arabidopsis G protein mutants.

Fig. S9. Length of Arabidopsis hypocotyls and cell number

Fig. S10. Abiotic stress responses of $\mathrm{G}$ protein mutants.

Fig. S11. Immune responses of $\mathrm{G}$ protein mutants.

Fig. S12. Genotyping of the gpa1-3 xlg1-1 xlg2-1 xlg3-1 quadruple mutant.

\section{REFERENCES AND NOTES}

1. N. Wettschureck, S. Offermanns, Mammalian G proteins and their cell type specific functions. Physiol. Rev. 85, 1159-1204 (2005).

2. D. Urano, J.-G. Chen, J. R. Botella, A. M. Jones, Heterotrimeric G protein signalling in the plant kingdom. Open Biol. 3, 120186 (2013).

3. S. R. Sprang, G protein mechanisms: Insights from structural analysis. Annu. Rev. Biochem. 66, 639-678 (1997).

4. W. Bradford, A. Buckholz, J. Morton, C. Price, A. M. Jones, D. Urano, Eukaryotic G protein signaling evolved to require G protein-coupled receptors for activation. Sci. Signal. 6, ra37 (2013).

5. J. C. Jones, J. W. Duffy, M. Machius, B. R. S. Temple, H. G. Dohlman, A. M. Jones, The crystal structure of a self-activating $\mathrm{G}$ protein $\alpha$ subunit reveals its distinct mechanism of signal initiation. Sci. Signal. 4, ra8 (2011).

6. Y. R. Lee, S. M. Assmann, Arabidopsis thaliana 'extra-large GTP-binding protein' (AtXLG1): A new class of G-protein. Plant Mol. Biol. 40, 55-64 (1999).

7. N. Maruta, Y. Trusov, E. Brenya, U. Parekh, J. R. Botella, Membrane-localized extralarge $\mathrm{G}$ proteins and $\mathrm{Gbg}$ of the heterotrimeric $\mathrm{G}$ proteins form functional complexes engaged in plant immunity in Arabidopsis. Plant Physiol. 167, 1004-1016 (2015).

8. D. Chakravorty, T. E. Gookin, M. J. Milner, Y. Yu, S. M. Assmann, Extra-large G proteins expand the repertoire of subunits in Arabidopsis heterotrimeric $\mathrm{G}$ protein signaling. Plant Physiol. 169, 512-529 (2015)

9. S. Pandey, G. B. Monshausen, L. Ding, S. M. Assmann, Regulation of root-wave response by extra large and conventional G proteins in Arabidopsis thaliana. Plant $\mathrm{J}$. 55, 311-322 (2008). 
10. L. Ding, S. Pandey, S. M. Assmann, Arabidopsis extra-large G proteins (XLGs) regulate root morphogenesis. Plant J. 53, 248-263 (2008).

11. H. Zhu, G.-J. Li, L. Ding, X. Cui, H. Berg, S. M. Assmann, Y. Xia, Arabidopsis extra large G-protein 2 (XLG2) interacts with the $\mathrm{G} \beta$ subunit of heterotrimeric $\mathrm{G}$ protein and functions in disease resistance. Mol. Plant 2, 513-525 (2009).

12. J.-G. Chen, Y. Gao, A. M. Jones, Differential roles of Arabidopsis heterotrimeric Gprotein subunits in modulating cell division in roots. Plant Physiol. 141, 887-897 (2006).

13. H. Ullah, J.-G. Chen, B. Temple, D. C. Boyes, J. M. Alonso, K. R. Davis, J. R. Ecker A. M. Jones, The $\beta$-subunit of the Arabidopsis $G$ protein negatively regulates auxininduced cell division and affects multiple developmental processes. Plant Cell 15 393-409 (2003).

14. H. Ullah, J.-G. Chen, J. C. Young, K.-H. Im, M. R. Sussman, A. M. Jones, Modulation of cell proliferation by heterotrimeric G protein in Arabidopsis. Science 292, 2066-2069 (2001).

15. K. M. Warpeha, S. S. Lateef, Y. Lapik, M. Anderson, B.-S. Lee, L. S. Kaufman, G-proteincoupled receptor 1, G-protein $\mathrm{G} \alpha$-subunit 1, and prephenate dehydratase 1 are required for blue light-induced production of phenylalanine in etiolated Arabidopsis. Plant Physiol. 140, 844-855 (2006).

16. X.-Q. Wang, H. Ullah, A. M. Jones, S. M. Assmann, G protein regulation of ion channels and abscisic acid signaling in Arabidopsis guard cells. Science 292, 2070-2072 (2001)

17. J. Harholt, $\varnothing$. Moestrup, P. Ulvskov, Why plants were terrestrial from the beginning. Trends Plant Sci. 21, 96-101 (2016).

18. K. Hori, F. Maruyama, T. Fujisawa, T. Togashi, N. Yamamoto, M. Seo, S. Sato, T. Yamada, H. Mori, N. Tajima, T. Moriyama, M. Ikeuchi, M. Watanabe, H. Wada, K. Kobayashi, M. Saito, T. Masuda, Y. Sasaki-Sekimoto, K. Mashiguchi, K. Awai, M. Shimojima, S. Masuda, M. Iwai, T. Nobusawa, T. Narise, S. Kondo, H. Saito, R. Sato, M. Murakawa, Y. Ihara, Y. Oshima-Yamada, K. Ohtaka, M. Satoh, K. Sonobe, M. Ishii, R. Ohtani, M. Kanamori-Sato, R. Honoki, D. Miyazaki, H. Mochizuki, J. Umetsu, K. Higashi, D. Shibata, Y. Kamiya, N. Sato, Y. Nakamura, S. Tabata, S. Ida, K. Kurokawa, H. Ohta, Klebsormidium flaccidum genome reveals primary factors for plant terrestrial adaptation. Nat. Commun. 5, 3978 (2014).

19. I. Sørensen, F. A. Pettolino, A. Bacic, J. Ralph, F. Lu, M. A. O’Neill, Z. Fei, J. K. C. Rose, D. S. Domozych, W. G. T. Willats, The charophycean green algae provide insights into the early origins of plant cell walls. Plant J. 68, 201-211 (2011).

20. D. Urano, J. C. Jones, H. Wang, M. Matthews, W. Bradford, J. L. Bennetzen, A. M. Jones, G protein activation without a GEF in the plant kingdom. PLOS Genet. 8, e1002756 (2012).

21. J. B. Heo, S. Sung, S. M. Assmann, $\mathrm{Ca}^{2+}$-dependent GTPase, extra-large G protein 2 (XLG2), promotes activation of DNA-binding protein related to vernalization 1 (RTV1) leading to activation of floral integrator genes and early flowering in Arabidopsis. $J$ Biol. Chem. 287, 8242-8253 (2012)

22. L. C. James, D. S. Tawfik, Conformational diversity and protein evolution-A 60-yearold hypothesis revisited. Trends Biochem. Sci. 28, 361-368 (2003).

23. J. A. Capra, M. Singh, Predicting functionally important residues from sequence conservation. Bioinformatics 23, 1875-1882 (2007).

24. D. G. Lambright, J. Sondek, A. Bohm, N. P. Skiba, H. E. Hamm, P. B. Sigler, The 2.0 A crystal structure of a heterotrimeric G protein. Nature 379, 311-319 (1996).

25. D. Urano, T. Dong, J. L. Bennetzen, A. M. Jones, Adaptive evolution of signaling partners. Mol. Biol. Evol. 32, 998-1007 (2015)

26. P. W. Day, J. J. G. Tesmer, R. Steme-Marr, L. C. Freeman, J. L. Benovic, P. B. Wedegaertner, Characterization of the GRK2 binding site of $\mathrm{G}_{\mathrm{q}}$. J. Biol. Chem. 279, 53643-53652 (2004).

27. J. C. Jones, B. R. S. Temple, A. M. Jones, H. G. Dohlman, Functional reconstitution of an atypical $G$ protein heterotrimer and regulator of $G$ protein signaling protein (RGS1) from Arabidopsis thaliana. J. Biol. Chem. 286, 13143-13150 (2011).

28. A. C. Colaneri, M. Tunc-Ozdemir, J. P. Huang, A. M. Jones, Growth attenuation under saline stress is mediated by the heterotrimeric G protein complex. BMC Plant Biol. 14, 129 (2014)

29. K. A. Lease, J. Wen, J. Li, J. T. Doke, E. Liscum, J. C. Walker, A mutant Arabidopsis heterotrimeric G-protein $\beta$ subunit affects leaf, flower, and fruit development. Plant Cell 13, 2631-2641 (2001)

30. F. Llorente, C. Alonso-Blanco, C. Sánchez-Rodriguez, L. Jorda, A. Molina, ERECTA receptor-like kinase and heterotrimeric $G$ protein from Arabidopsis are required for resistance to the necrotrophic fungus Plectosphaerella cucumerina. Plant J. 43, 165-180 (2005).

31. Y. Chen, F. Brandizzi, AtIRE1A/AtIRE1B and AGB1 independently control two essential unfolded protein response pathways in Arabidopsis. Plant J. 69, 266-277 (2012).

32. X. Liang, P. Ding, K. Lian, J. Wang, M. Ma, L. Li, L. Li, M. Li, X. Zhang, S. Chen, Y. Zhang, J. M. Zhou, Arabidopsis heterotrimeric $G$ proteins regulate immunity by directly coupling to the FLS2 receptor. Elife 5, e13568 (2016).

33. D. Urano, A. M. Jones, "Round up the usual suspects": A comment on nonexistent plant G protein-coupled receptors. Plant Physiol. 161, 1097-1102 (2013).

34. S. A. Rensing, D. Lang, A. D. Zimmer, A. Terry, A. Salamov, H. Shapiro, T. Nishiyama, P.-F. Perroud, E. A. Lindquist, Y. Kamisugi, T. Tanahashi, K. Sakakibara, T. Fujita, K. Oishi, I. T. Shin-I, Y. Kuroki, A. Toyoda, Y. Suzuki, S.-I. Hashimoto, K. Yamaguchi, S. Sugano, Y. Kohara, A. Fujiyama, A. Anterola, S. Aoki, N. Ashton, W. B. Barbazuk, E. Barker, J. L. Bennetzen, R. Blankenship, S. H. Cho, S. K. Dutcher, M. Estelle, J. A. Fawcett, H. Gundlach, K. Hanada, A. Heyl, K. A. Hicks, J. Hughes, M. Lohr, K. Mayer, A. Melkozernov, T. Murata, D. R. Nelson, B. Pils, M. Prigge, B. Reiss, T. Renner, S. Rombauts, P. J. Rushton, A. Sanderfoot, G. Schween, S.-H. Shiu, K. Stueber, F. L. Theodoulou, H. Tu, Y. Van de Peer, P. J. Verrier, E. Waters, A. Wood, L. Yang, D. Cove, A. C. Cuming, M. Hasebe, S. Lucas, B. D. Mishler, R. Reski, I. V. Grigoriev, R. S. Quatrano, J. L. Boore, The Physcomitrella genome reveals evolutionary insights into the conquest of land by plants. Science $\mathbf{3 1 9}$, 64-69 (2008)

35. Y. Trusov, D. Chakravorty, J. R. Botella, Diversity of heterotrimeric G-protein $\gamma$ subunits in plants. BMC Res. Notes 5, 608 (2012)

36. L. Thung, Y. Trusov, D. Chakravorty, J. R. Botella, $\mathrm{G} \gamma 1+\mathrm{G} \gamma 2+\mathrm{G} \gamma 3=\mathrm{G} \beta$ : The search for heterotrimeric G-protein $\gamma$ subunits in Arabidopsis is over. J. Plant Physiol. 169, 542-545 (2012)

37. A. Feduccia, Riddle of the Feathered Dragons: Hidden Birds of China (Yale Univ. Press, 2012).

38. K. Katoh, D. M. Standley, MAFFT multiple sequence alignment software version 7: Improvements in performance and usability. Mol. Biol. Evol. 30, 772-780 (2013)

39. K. P. Schliep, phangorn: Phylogenetic analysis in R. Bioinformatics 27, 592-593 (2011).

40. B. Webb, A. Sali, Protein structure modeling with MODELLER. Methods Mol. Biol. 1137, 1-15 (2014)

41. G. E. Crooks, G. Hon, J.-M. Chandonia, S. E. Brenner, WebLogo: A sequence logo generator. Genome Res. 14, 1188-1190 (2004).

42. C. A. Johnston, J. P. Taylor, Y. Gao, A. J. Kimple, J. C. Grigston, J.-G. Chen, D. P. Siderovski, A. M. Jones, F. S. Willard, GTPase acceleration as the ratelimiting step in Arabidopsis G protein-coupled sugar signaling. Proc. Natl. Acad. Sci. U.S.A. 104, 17317-17322 (2007).

43. Y. Trusov, D. Chakravorty, J. R. Botella, Fusarium oxysporum infection assays in Arabidopsis. Methods Mol. Biol. 1043, 67-72 (2013).

Acknowledgments: We thank C. Jones, A. Urano, and C. Santos for technical assistance. Funding: This work was supported by grants from the National Institute of General Medical Sciences (R01GM065989) and NSF (MCB-0718202) to A.M.J. The Division of Chemical Sciences, Geosciences, and Biosciences, Office of Basic Energy Sciences of the U.S. Department of Energy, through grant DE-FG02-05er15671 to A.M.J., funded technical support in this study. J.R.B., Y.T., and N.M. acknowledge funding from the Australian Research Council. N.M. is the recipient of a University of Queensland International PhD scholarship. Author contributions: D.U. designed experiments, obtained data, performed analyses, and wrote the manuscript. A.M.J. designed experiments, obtained data, and wrote the manuscript. R.S., Q.W., Y.L., L.T., and D.K.J. collected data. N.M. and Y.T. obtained data and edited the manuscript. J.R.B. and D.J. supervised experiments and edited the manuscript. Competing interests: The authors declare that they have no competing interests. Data and materials availability: Arabidopsis mutant lines and plasmids mentioned in this article are available from A.M.J. or D.U.

Submitted 25 April 2016

Accepted 29 August 2016

Final Publication 20 September 2016

10.1126/scisignal.aaf9558

Citation: D. Urano, N. Maruta, Y. Trusov, R. Stoian, Q. Wu, Y. Liang, D. K. Jaiswal, L. Thung, D. Jackson, J. R. Botella, A. M. Jones, Saltational evolution of the heterotrimeric G protein signaling mechanisms in the plant kingdom. Sci. Signal. 9 , ra93 (2016). 
Science Signaling

MAAAS
Saltational evolution of the heterotrimeric $\mathbf{G}$ protein signaling mechanisms in the plant kingdom

Daisuke Urano, Natsumi Maruta, Yuri Trusov, Richard Stoian, Qingyu Wu, Ying Liang, Dinesh Kumar Jaiswal, Leena Thung, David Jackson, José Ramón Botella and Alan M. Jones (September 20, 2016)

Science Signaling 9 (446), ra93. [doi: 10.1126/scisignal.aaf9558]

The following resources related to this article are available online at http://stke.sciencemag.org.

This information is current as of September 21, 2016.

Article Tools Visit the online version of this article to access the personalization and article tools:

http://stke.sciencemag.org/content/9/446/ra93

\section{Supplemental}

Materials

Related Content

References

Permissions
"Supplementary Materials"

http://stke.sciencemag.org/content/supp1/2016/09/16/9.446.ra93.DC1

The editors suggest related resources on Science's sites: http://stke.sciencemag.org/content/sigtrans/6/276/ra37.full http://stke.sciencemag.org/content/sigtrans/4/159/ra8.full http://stke.sciencemag.org/content/sigtrans/9/417/re2.full http://stke.sciencemag.org/content/sigtrans/7/352/ra109.full http://stke.sciencemag.org/content/sigtrans/5/222/ra35.full http://science.sciencemag.org/content/sci/343/6172/780.full http://stke.sciencemag.org/content/sigtrans/9/446/eg9.full

This article cites 42 articles, 23 of which you can access for free at: http://stke.sciencemag.org/content/9/446/ra93\#BIBL

Obtain information about reproducing this article: http://www.sciencemag.org/about/permissions.dtl

Science Signaling (ISSN 1937-9145) is published weekly, except the last December, by the American Association for the Advancement of Science, 1200 New York Avenue, NW, Washington, DC 20005. Copyright 2016 by the American Association for the Advancement of Science; all rights reserved. 